repeat the retinoscopy, and the subjective test with the correction worked out by retinoscopy.

6. Finally, a week later the subjective test should be repeated before glasses are ordered.

The worker must keep a note-book in which to enter a record of each step of the examination of each patient in full detail, with comments on any difficulty met with. When he has followed out this programme with a score or two of intelligent patients, and studied the results after each day's work, he will be in a position to judge of the value and accuracy of his work; and he will also have obtained valuable knowledge of the differences between subjective tests of an eye of unknown differences between subjective tests of an eye of unknown condition, retinoscopy with and without an myriatic, and the differences, if any, ketween quick and slow acting drugs, and finally of subjective tests with all the available data before him... Only by a continuous course of practice such as outlined here, in which he can check his objective work by the subjective examination of critioal patients, can he cultivate a mastery of objective methods and free himself from the thraldom of reliance upon sabjective responses.

I have written an account of the methods of retinoscopy that I find best to use and teach, ${ }^{1}$ so that I propose here to deal only with one point-the best method of finding the axis of astigmatism by the use of the retinoscopy mirror.

Astigmatism is due to an inequality of the refractive index of the optical combination of the eye; the inequality can be seen and measured by retinoscopy. It may be ob. scured at first examination by the presence of a spherical error; as that error is corrected the fact that there is more error in one meridian of the eye than in another will be revealed. The revelation of the defect is sometimes, when the error is high, quite dramatic. The light reflex from the eye may assume the appearance of a pillar of fire. The pillar may be erect, running vertically across the pupil, or it may have an inclination or slope from the per. pendicular; it may even be horizontal. It is the observance of this inclination that gives the axis of the astigmatism.

Take a plus cylinder of six or seven dioptres, look through it at a distant circular light, such as may be obtained by placing a at a distant circular light, such as mar be obtained or placing a screen plerced of light will be seen to be distorted into a line, lamp; the circle of light will be seen to be distorted the line of and as the cylinder is slowly rotated before the ere the line of light will turn also; it will only need a method of marking the inclination of this line of ligh

cylinder held before the eye.

The axis of a cylinder is recorded by noting the position it takes on a circle or half-circle marked in degrees. Most students are familiar with certain standards of measure. ments; probably all could mark on paper with fair accuracy the measure of an inch, a centimetre, or millimetre; most women can judge a yard with surprising skill. We do these things because we are familiar with the measure, and associate it unconsciously perhaps with some concrete object. But you are not familiar witb the degrees of a circle, for this measure does not often enter into everyday life. To obtain this familiarity I would refer you to something you know well-the familiar clock face; the hour marks on the face will give the salient points of the degrees of a circle.

If we take the hour mark of IX as $0^{\circ}$ and III as $180^{\circ}$, then VIII will be $30^{\circ}$, VII $60^{\circ}$, VI $90^{\circ}$, V $120^{\circ}$, IV $150^{\circ}$. Apply this observation by association to the judgement of the inclination obseriation oy association to the judgement of the inclination of the line of light seen in retinoscops of astigmatism. Note the time that would be indicated if the line of light were the outstretched hands of the clock, if it indicated five minutes to five o'clock the inclination in degrees would be 120 . With practice, and a constant cross-reference between time of the clock and degrees of the circle, the worker will be able to reacl off the axis of an astigmatism from the eye itself as accurately, and subjective examination.

Practice in direct observation should be checked by reference to the markings of the degrees on the cell of the trial frame. There are two useful methods of doing this:

1. Take a thin blackened disc of metal the size of a trial lens, bore throngh the centre a $10 \mathrm{~mm}$. hole, and mark the diameter on the remaining part of the disc by a line of white paint just broad enough to be seen at one metre. Slip this disc into the cell of the trial frame so that the patient's pupil can be seen through the hole. Note the line of light due to the astigmatism and its inclination, and estimate the axis in degrees. Then and its inclination, and estimate the axis in degrees. Then rotate the disc in the trial frame until the painted white line is in continuity with the line of the astigmatism, note the position of the paint line to the marking on the trial frame. If the two
observations, the direct observation and the position of the observations, the direct observation and

2. Correct the spherical part of the error of refraction br the use of spherical lenses, when the astigmatism is revealed correct this by the use of cylinders, placing each cylinder in the cell of the frame so that its axis coincides with the line of the astigmatism. If now the spherical correction be slightl altered so as to leave half a dioptre of hypermetropia, the light reflex due to this direction, and witherical error should move equally in every movion, and without wobble or sign of obliquity with test.

Practice of these three methods, comparing direct observation with the findings obtained with the aid of disc or cylinders, will show that it is possible in the majority of cases to measure the astigmatism both in amount and axis by the use of the mirror and spherical lenses alone; and the use of cylindrical lenses may be reserved for the few cases of real difficulty.

A concluding note may be made on the method of recording the axis of cylinders ordered in prescriptions. Unfortunately, there are many markings in use. Examine a dozen trial frames of different makes and as many prescription forms: the variations found will be striking. An attempt has been made to obtain an international a ment, and the form arrived at can be appreciated by reference to the clock face. For each eye, right and left, the degree markings that correspond with the hour marks on the clock face are $Q^{\circ}$. at IX o'clock and $180^{\circ}$ at III o'clock. Since this marking is obtaining a wide measure of acceptance it is woith while learning it, for if you use another it is likely your prescription will be transcribed by the optician, and errors may occur in transcription. In any. case. always mark the axis graphically as well as numerically, then the possibilities of error will be reduced to the minimum.

REFERENCE.

1 dids to Ophthalmology. Sixth edition. 1919. London: Baillièro, Tindall, and Cox.

\section{A NOTE ON LYMPHADENOMA.}

BY

GEORGE J. LANGLEY, M.D.LoND., M.R.C.P.,

ASSISTANT PHYSICIAN, SALFORD ROTAL HOSPITAL; PHYSICIAN, axCOATS HOSPITAL, MANCHESTER.

ThE following case, which has been under hospital observation almost throughout its clinical course, offers so many points of interest with regard to diagnosis that it may be worth while recording at some length.

G. K., a single man aged 24 , had always been healthy except for an attack of scarlet fever at 7 years of age. There was no family history of tuberculosis or any other disease, nor of any other illness in the patient prior to enlistment in November, 1915. He was demobilized in May, 1919, having served two years in France and having been twice in hospital, once with tonsillitis in 1916, and once being invalided home with myalgia in 1917, recovery talking place in six months. After demobilization the patient returned to his civil employment as a grocer's assistant until November, 1919, when rheumatism in his shoulders and back caused him to give up work.

In January, 1920, he became an out-patient at a pensions hospital, but owing to the development of a left basal pleurisy he became too ill to attend. In March, 1920, a swelling was noticed in the right axilla, which quickly disappeared, only to be followed by similar swellings in the left axilla and right side of the neck. The patient became gradually very pale, lost weight, and grew progressively weaker, but was not entirely bedridden till admission to hospital on April 23rd, 1920. He then complained of night sweats, and rheumatism in tho back, shoulders, and right knee.

\section{Condition on Admission.}

On admission the patient was pale and wasted, with obvious masses of enlarged glands in the neck. On examination, both sides of the neck and the submaxillary region were filled with enlarged discrete glands, very various in size from a pea to a walnut and with little or no periadenitis. Both axillae showed a similar condition and the right epitrochlear gland was as large as a filbert, but the left could not be felt. Both groing large a a showed many enlarged glands extending along Poupart's liga ment both above and below it. The popliteal glands could not be felt. There was a large crop of subcutaneous and intranot crossing the mid-line in front nor the posterior axillary line 
behind; some looked slightly inflamed with a hyperaemic apex. They varied in size from a hazel nut to just palyable masses. The heart showed a cardiac dullness extending upwards to the third costal cartilage and to the right 1 in. beyond the right sternal edge, the apex beat was in the fifth space in the nipple line, cardiac sounds were feeble, and there was a precordial systolic nurmur not conducted. The pulse rate was 116 per minute, regular, but of poor volume and low tension. Chest movements were normal and the breath sounds healthy, except for a slight friction rub at the right base productive of some for a slight friction rub at the right base productive of some
pain and cough. Percussion resonance was normal, except pain and cough. Percussion resonance was normal, except the fourth thoracic vertebra on both sides where resonance was

diminished.

The liver dullness in the nipple line extended from the sixth rib to the costal margin where its edge was felt to be even, firm, and not tender. Splenic dullness in the midaxillary line extended from the tenth rib to the tip of the organ, which was just felt below the ribs. In the right iliac fosse a mass of glands was felt resting against Poupart's ligament and apparently continuous a ligant as in the All reflexes tiere found to be normal; the urine was alkaline,

specific gravity 1020, and it contained no albunin. A skiagram showed the right diaphragm slightly raised, the size of the liver and spleen was not determined, the posterior mediastinum was somewhat obscured, probably by enlarged

A blood count gave the following results:

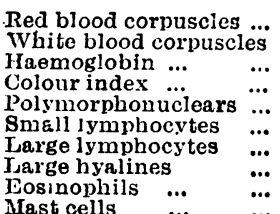

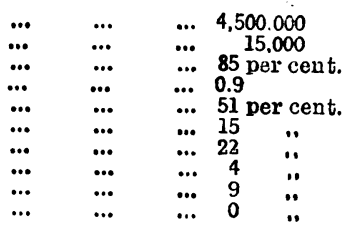

My surgical colleague, Mr. Jefferson, kindly removed for histological examination $(a)$ a gland from the left groin and $(b)$ a nodule from the skin of the right chest wall.

On séclion both tumours showed the typical changes of lymphadenoma, with small giant cells containing three or four deeply-staining nuclei, a large number of eosinoplils, and an increased fibrosis.

Throughout the whole illness the patient ran a tem. perature of about $101^{\circ} \mathrm{F}$. at night and normal in the morning, except for about a fortnight in early July, when the temperature remained normal. At no time did he show the typical Pel-Ebstein temperature variation.

The patient was given large doses of arsenic for long periods and regular $x$-ray exposures. In spite of this, the course of the disease was slowly but progressively down. wards. The only time of apparent improvement was during the period of apyrexia in early July. The $x$-ray treatment produced very considerable results on the glands, those in the neck completely disappearing, twhile those in the axillae and groins were very materially reduced. On the other hand, the cuiancous nodules were not at all affected and continued to grow slowly, desquamation and redness occurring over the larger ones in spite of protection by cotton-wool. In August a mass appeared at the second left chondro-sternal junction which appeared to rise from bone, and which grew to the size of half a Tangerine orange, being firmly fixed both to bone and skin. $\AA$ few weeks later a mass appeared at the back of the neck which appeared to arise from the lower cervical vertebrae. In November a nodule the size of a walnut at the right anterior axillary fold broke down and ulcerated, having a crateriform, granulating, hyperaemic surface and a central yellowish slough. About this time a large, indefinite softish mass could be felt in the right lower abdomen which appeared to be an infiltration of the caecum and ascending colon. The liver and spleen became impalpable very shortly after commencing $x$-ray treatment, and the liver did not again become palpable till definite signs of cardfac failure with ascites and oedema had appeared; it was then firm and tender, but the spleen could not be felt.

The patient suffered much pain throughout the illness. In the chest this was due to tiansient pleural friction in the region of the liver or spleen. Pain in the long bones was complained of from time to time, but the chief pain was abdominal, although at no time was there any vomiting or bowel trouble. The patient was extremely anaemic throughout and became very emaciated. No symptoms of mediastinal pressure ever occurred. The masses arising from bone never appeared to cause pain. The total dura. tion of the disease was almost exactly a jear, death occuring at the end of November. Unfortunately permission for post-mortein examination was witliheld.

The changes which occurred in the blood picture are indicated in the following table, with dates:

\begin{tabular}{|c|c|c|c|c|c|c|}
\hline & & & & May 22, 1920. & Aug. 6,1920. & Oct. 31, 1920. \\
\hline Red blood corp & uscles & & $\ldots$ & $4,560,000$ & $5,100,000$ & $3,100,000$ \\
\hline White blood co & rpusc & ies & ... & 15,050 & 27,500 & 32,500 \\
\hline Polymorphs & ... & $\ldots$ & $\ldots$ & 51 per cent. & 69 per cent. & 75 per cent. \\
\hline Small lymphoc & stes & $\ldots$ & $\ldots$ & $15 \quad$ & 10 & " \\
\hline Large lymphoc & ytes & $\cdots$ & $\ldots$ & 22 & 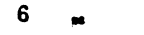 & 10 \\
\hline Large hyalines & ... & $\cdots$ & $\ldots$ & " & ״ & 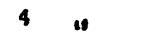 \\
\hline Eosinophils & $\therefore$ & $\ldots$ & $\cdots$ & ". & 11 & 12 \\
\hline Mast cells & $\ldots$ & ... & $\ldots$ & - & - & $\rightarrow$ \\
\hline Haemoglobin & $\ldots$ & ..e & $\cdots$ & 85 per cent. & 90 per cent. & 60 per cent. \\
\hline Colour index & $\ldots$ & $\cdots$ & $\cdots$ & 0.9 & 0.9 & 1.0 \\
\hline
\end{tabular}

The interest of this case lies in the difficulty of clinical diagnosis. The growths in the skin suggested at once that the case was not one of lymphadenoma but of lymphosarcoma. The absence of any marked splenic enlargement and the type of fever, which did not conform to the Pel-Ebstein sequence, strengthened the view of its malignant nature. On the other hand, the blood picture and the quite remarkable response to $x$-ray treatment strongly suggested lymphadenoma. The appeal to histological inquiry-the only possible method of arriving at a conclusion-quickly settled the nature of the disease, but helped not at all in explaining its unusual character.

The recognized occurrence of cutaneous nodules in lymphatic leukaemia added some support to the theory that the case might be regarded as the pre-leukaemic state of leukaemia, but such alteration of the blood picture as did occur was in a direction away from typical lymphatic leukaemia. The occurrence of tumour masses in the bones (manubrium sterni, vertebrae) suggested the possibility of lymphadenia ossium, but these masses ap. peared late as an incident in the disease, rather than as the basic fact of it.

Tho cutaneous masses remained discrete, and did not tend to coalesce. The single mass which ulcerated did not proliferate nor fungate, the process being very slow and apparently more due to pressure than to active growth. All this was very unlike the descriptions of mycosis fungoides. The blood picture corresponded in some measure with the findings of Bunting ${ }^{1}$ in lymphadenoma cases, in that it showed a fall in lymphocyte and eosinophile count with a rise in polynuclears as the disease progressed. The occurrence of these tumour masses in skin and bone becomes more intelligible when they are considered in the light of the view put forward by Adami that they are not to be regarded as metastases, but as hypertrophies arising in the lymphoid tissue of the perivascular sheaths. By this theory their occurrence in any site is explainable.

My thanks are due both to Dr. W. J. S. Bythell for $x$-ray reports and to Dr. C. E. Jenkins for much pathological help.

1. REFERENCE:

1 Bunting: Johns Hopkins Hospitul Bulletin,
2 Adami : Principles of Pathology, vol, i, p, 740.

A COURSE has been arranged by the London School of Aedicine for Women for the instruction of qualifled medical women in the treatment of venereal diseases at the Royal Free Hospital, the Elizabeth Garrett Anderson Hospital, and the London Lock Hospital. 'The course, which will begin on Tuesday, May 17 th, at 10 a.m., when Mr. J. E. R. McDonagh, will give an introductory lecture on "Some aspects of the venereal problem," will extend over two weeks, concluding on Saturday, May 28th. The Ministry of Health recognizes attendance at this course as qualifying a medical practitioner who has pursued it to receive free drugs for the treatment of venereal diseases. Qualifhed medical women who wish to attend the course are askd to send in their names to Miss L. M. Brooks, warden and secretary of the medical school, not less than seven days before the course begins; the fee for the full course will be 5 guineas. 